\title{
LA ESENCIAL ANALOGÍA
}

Humberto Vinueza*

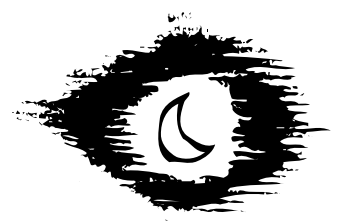

1.- Sensación de que la membrana de una palabra es acariciada por la música lejana de otra. Sombra y destello en la vibración del instante, mientras discurre una conversación, en la evocación o el arrobamiento ante el paisaje cósmico, en la lectura de poemas de otros poetas que ya son propios o de los propios que pertenecen a la plural humanidad. Estremecimiento entre la somnolencia y el viaje onírico, estando bajo la ducha, comiendo, pensando en escalones, pasos, niveles, jerarquías, sistematizaciones, conclusiones, pre(con)ceptos, en el momento en que se cohesiona, tal vez se dispersa un perfume o se escucha el grito unánime de gol en el

* Escritor, miembro de la Casa de la Cultura Ecuatoriana. 
paleolítico. Una palabra llama a otra, la seduce, le tiende trampas, pero no siempre el verso se constela. Felizmente, casi nunca ocurre la precipitación del poema, o quizá uno se las ingenia para que no siempre ocurra. Intuyo que esto sucede cuando interfieren elementos que no armonizan entre sí en algún fondo desconocido, inasible. Puede ser que por falta de atención la ráfaga no se fije en la memoria consciente. En otras ocasiones la voz llama con intermitencia en cualquier momento, en todos los momentos, incluso en el servicio higiénico, en el autobús, haciendo el amor, volteando la esquina equivocada, trasponiendo el umbral de cualquier edad bajo la lluvia, ante un árbol rociado con las luces rojas del crepúsculo. Y se torna pertinaz el aullido sin abecedario o el llamado desde toda la lengua. $Y$ al fin, en medio de camaretas y cohetes sensibles se produce la significación en el verso que ilumina la diferencia, la humana identidad, hecha con el poder de natura que fluye hacia el alumbramiento con júbilo de unidad primigenia, pero también con palabras insustituibles e indispensables silencios, bajo los devaneos de la embriaguez de alguna certeza. Unas veces se configura con la invisibilidad y otras, con la voz desnuda del lenguaje, siendo ambas conjetura y presencia en cual- quier tiempo. No hay medias tintas: se trata de la vital aventura de la poesía, de la encarnación del ser en la palabra, jugando a ser otro ¿para ser él más mismo? ¿Para ser espacio escénico ilusorio, hecho con rasgos de sueño real y restos de vigilia inverosímil? ¿Dramaturgia sin sujeto definido, donde el ser conspira contra el orden social o divino? ¿Embrujo, artificio, probabilidad perpleja? ¿Cábala que se muestra sin que el enigma sea descifrado?

2.- En uno de mis primeros poemas, escrito cuando yo era un poco más que adolescente, traté de expresar la sensación de que mi ser estaba hecho de la misma sustancia que la de los otros seres y percibía que hay un límite o un contorno que debe ser protegido para mantener la particularidad singular. El poema contenía los siguientes versos: soy una gota /rodeada de elemental analogía /de hombre /de sangre /de agua. /Mi piel conviene en que no sólo soy frontera. Más tarde, a través de la lectura descubrí en los Cuatro Cuartetos, de Eliot, un verso parecido, pero no igual que dice: the river is within $u s$, Ithe sea is all about us..., que traducido significa: el río está en nuestro interior, lel mar nos cerca por todos lados. En vez de sentirme defraudado por mi vulnerable originalidad, na- 
ció en mí una actitud de entereza, de orgullosa altivez y, al mismo tiempo, de entusiasta ponderación por haber encontrado coincidencias con otro poeta, sin importarme si era famoso o no. Desde aquel entonces desconfío de la noción de originalidad ligada solamente al imán de la tradición o sólo al intento de novedad, quizá porque el poema absolutamente original es absolutamente malo; es, en el mal sentido, subjetivo, sin relación con el mundo al que apela, afirma el mismo Eliot. La originalidad, en otras palabras, es sin duda una imprecisa invención de la crítica poética. La originalidad es un pecado de jactancia, decían en la edad media. Pero si el esfuerzo de originalidad es un deseo de jugar, de estar en otro de un modo distinto y conduce a lo extraordinario y a la celebración, que es el salto de la realidad en la cuerda de la infancia, entonces la existencia es una trama de instantes que perduran reorientando el rol de la memoria, y tal vez por eso debamos vivir cada palabra como si fuera la última. Bienvenida la originalidad si ella es la posibilidad de perfeccionar el lenguaje (metáforas, metonimias, antonomasias, homologías, analogías, alegorías, intertextualidades, enigmas, parodias, hipérboles, ritmos, zigzagueos, silencios, hendeduras, entresijos, espe- jeos) para poner en movimiento el propio ser, porque el poeta no está totalmente hecho, es inacabado, tiene que hacerse y no podrá completarse en el encierro y la incomunicación, sino en la convivencia con los ciudadanos y las peripecias en la urbe que le tocó vivir, llena de laberintos de paisajes y calles que trepan hacia el cielo a través de los cerros, de ir y venir de transeúntes que en medio del apretujamiento, el sobresalto y la sin salida parecen que se dijeran a sí mismos: no es suficiente con afirmar que el mundo es así, que la condición humana es invariable como las escenas en las audiencias crecientes del 'reality show'. Habría que añadir la mala suerte, el azar o el destino que son implacables y feroces, en el escenario de la disputa simbólica dentro de nuestras ciudades convertidas en un mundo poblado de gorgonas -como decía alguien-, al que le sobran héroes y víctimas y le faltan ciudadanos. Ansias de trascendencia también, que hacen que se renuncie a la armonía, al deseo de simetría; se acepte estoicamente la unidad irreconciliable de las partes del ser en conflicto, la validez y la carencia tácitas del mestizaje. Entre la gente, con César Vallejo alguien preguntará: ¿Por ahí estás, Venus de Milo? /Tú manqueas apenas pululando lentrañada en los brazos 
plenarios /de la existencia, /de esa existencia que todaviiza/perenne imperfección. Por ésta y otras razones, considero que hay causas ennoblecidas por la necesidad que debemos enarbolarlas y es posible encontrarlas, como es posible aprender a distinguir el canto de los pájaros, la ubicación de los astros en el firmamento del ser amado, pretender leer el destino en los pliegues únicos del iris del ojo o simplemente leer y escribir, en contraposición a la sordi$\mathrm{dez}$, la mezquindad, el disparate con los cuales nos regodeamos -en reciprocidad o por propia iniciativa- en la relación con nuestros semejantes. Ha pasado mucho tiempo y mucha poesía se ha tejido desde y con aquellos versos que por primera vez los reconocí como míos. Ahora el miedo tiene un rostro enmarañado con una mueca a veces focalizada, otras veces difusa. ¿Qué haría yo y qué escribiría si no tuviera miedo? En el ámbito de la esencial analogía, mi piel, o sea todo mi cuerpo, sigue siendo no sólo un convenido límite, rodeado de elementalidad humana y de mundo, sino una frontera para compartirla.

3.- Definir la poesía es un brete, una quimera loca o cuerda, algo que no puede concretarse. $i S e$ puede definir la vida, el verdadero origen del tiempo, la magia de los encuentros, la tentación religiosa, la certidumbre de la muerte, la materia de la música, la identidad esencial, el extrañamiento en sí porque sí, el amor a primera vista? La explicación de lo incomprensible que es la poesía, solamente es posible por un único camino que es el acto de crearla de nuevo, de crearse con ella, desde ella. Aunque parezca una tautología, la creación sólo se torna tangible y recuperable por la creación, como si fuera la primera vez, como si nunca antes hubiera sido hecha o hubiera existido. Algún poeta dijo que la poesía es ese no sé qué, escrito por no sé cuál, que no sé sabe cuándo ni inspirado por quién. Y otro dijo que la poesía es una aventura hacia el absurdo. Y uno más dijo que la poesía es, entre todas las aguas que corren, la que menos se demora en los reflejos de los puentes. Y otro: la poesía es el arte de aproximarse a lo que nos sobrecoge. Y otro: la poesía es el instrumento de conocimiento y revelación de la verdad. Y otro: la poesía es el arte de escribivir. Y otro: a veces la poesía es el vértigo de los cuerpos y el vértigo de la dicha y el vértigo de la muerte. Y él mismo: la poesía es el solo de flauta en la terraza de la memoria y el baile de llamas en la cueva del pensamiento. Y otro: la poesía es el dolor más antiguo. Y otro: "la significación de la poesía no es la presencia 
de una idea. Y otro: la poesía no está en las cosas, porque de lo contrario todo el mundo la descubriría fácilmente en ellas. Y otro: la poesía es hasta ahora la única posibilidad de poder aislar un fragmento, extrayéndole su central contracción o de lograr arañar una hilacha del ser universal. Y otro: la poesía es el único sueño en el que no se debe soñar. Y otro: desde la poesía, el poeta nos pide ayuda y al mismo tiempo nos sosiega.

Y otro: no es la poesía la que debe ser libre, sino el poeta. Y otro: la poesía es el único lugar donde el poder de los números no significa nada. Y otro: la poesía es Dios en los sueños sagrados de la tierra. Y otro: poesía: que seas almendra sin cáscara. Y alguien del pueblo dijo: la poesía es como cuando uno no sabe qué ni como decirlo, y lo dice. Mi profesor de la cátedra de Edafología dijo una mañana de invierno siberiano: la poesía es el humus para el crecimiento de las semillas de todas las artes y las ciencias. Hasta aquí todo es fácil y está claro ¿verdad? Pero hay que regarlas con sudor, lágrimas, sangre. $Y$ con el agua de todos los tiempos.

4.- Se dice que el poema se revela como invención de realidad, porque es su reverso insospechado. El poema es un viaje que nos hace sentir la turbulencia de la intuición y del saber

\author{
Proceso de imaginar \\ que es la condición \\ esencial sin la cual no \\ es posible reconocer \\ ningún tipo de realidad.
}

total, nos conduce de la ausencia a la presencia, de lo visible a lo invisible, de la proferición al silencio, donde el pez sólo puede salvarse en el relámpago. Cuando hablamos de realidad entendemos por ella lo conocido y desconocido que en lo fundamental siempre es, lo que existe más allá y más acá de los sentidos, no obstante su afirmación o negación, lo irremediablemente contrario de la nada. La realidad es entonces lo consistente, lo permanente, lo sostenible y sustentable para emplear palabras que todavía están de moda. La realidad consiste en el ser que es, lo que subsiste frente a cualquier cambio. La poesía es una forma del pensar del ser que siempre ha sido, es y será, si bien pensamiento, distinto al racional, al de la abstracción, pero pensamiento con todos los alcances de su significación. La diferencia radica en que la poesía, más que representar descubre y augura realidad, a condición de que 
se invente en el poema. Inventar es la presencia de la voz que interroga por la voz que revela. El poetizar se manifiesta visión que crea lo que ve y, simultáneamente, ve de la misma manera cómo fue creado. Siendo una visión pensante que crea lo que ve, a través de palabras ensambladas de un único y sensitivo modo, la poesía funciona como una mirada verbal que mira con grafías de sonidos y sentido. La visión cobra forma real mientras brota la consistencia del poema y sólo puede ser leída con el código que recupera el origen y la naturaleza de la realidad poetizada, siendo no solamente lenguaje, sino algo más substancial, hecho de pensamiento, de sustrato de todos los otros sedimentos formales de la obra del poeta. Proceso de imaginar que es la condición esencial sin la cual no es posible reconocer ningún tipo de realidad. La realidad es no solamente más fantástica de lo que suponemos, sino la fuente inagotable de fantasía. Se ha dicho que mientras escribe el poeta no sabe cómo será su poema. En verdad, lo sabrá cuando ya terminado lo lea. El autor es el primer lector de su poema y con su lectura se inicia una serie infinita de interpretaciones y recreaciones. Cada lectura produce un poema distinto. Ninguna lectura es definitiva y, en este sentido, cada lectura, sin excluir a la o las del autor, es o son un accidente del poema. Soberanía del texto sobre su autor-lector y sus lectores sucesivos. El poema, es la vida del poeta que puede ser leída desde la vida del lector, dice Octavio Paz. En cada lectura se incorpora más vida del lector al texto del poema y, al mismo tiempo, más poema, o sea vida del autor-poeta, a la vida del lector. El poeta es cada vez más nosotros y cada uno de nosotros somos nervios y corazón abiertos a todos los poemas de todos los poetas.

5.- Para el poeta es importante el estatuto de la soledad, pero no como condición sediciosa y obstinada, sino como el distanciamiento táctico que le permita acortar o agrandar la distancia entre el hombre y los objetos, entre el hombre y sus congéneres, entre el hombre y sus únicas tres certezas: su nacimiento, su impotencia ¿perentoria?- de trasponer físicamente los linderos de la Vía Láctea y su muerte. La escritora norteamericana, premio Nobel, Toni Morrison dice: Morimos. Ese debe ser el significado de la vida. Pero construimos lenguaje, esa debe ser la medida de nuestras vidas. En este enfrentamiento, especialmente con la muerte, la poesía ha descubierto que lo que el hombre necesita no son afirmaciones, es posible que tampoco negaciones, ya que tanto las unas como las otras son 
sólo meros intentos $\mathrm{y}$, a veces, pasmados impulsos de imposibles. Según el poeta Juarroz, y antes que él, en algún sentido, Coleridge, lo que la poesía busca no es el confortable recurso de una respuesta, sino algo mucho más comprometido y más importante para el hombre, que es, ante la imposibilidad de respuestas, crearle presencias que lo acompañen. Sin contradecir, hay que añadir que la poesía crea compañías, concomitancias y enlaces, o sea capacidad de concurrencia y aproximación para la vida. La poesía hace posible atraer y ensamblar realidades lejanas $\mathrm{u}$ opuestas y transforma los términos distantes en una nueva identidad. Al configurar una presencia o una compañía, recobra y fija la pluralidad de significados. Los poemas, propios o ajenos, para determinadas personas cumplen una función propiciatoria de seguridad o de extensión del ser buscando la interrelación con las fuerzas superiores, como ocurre con los exvotos adheridos a las imágenes cristianas, las máscaras de algunas culturas del Asia o del África que cumplen distintas misiones desde este lado de la existencia con el supramundo y el inframundo o las figurillas providente de fertilidad, llamadas venus de Valdivia, en la cultura sedentaria más antigua de América. Conocí a alguien que para paliar sus depresiones leía con devoción el poe- ma Frente a la Tabaquería, de Pessoa. Y otro, ante la angustia de su exilio solía supersticiosamente leer cualquier poema del Canto a mí mismo, de Withman. Recuerdo que un poeta ya difunto, quien en vida fuera bisexual, decía que su principal e infalible arma de seducción era la lectura del poema La unión libre, de Bretón. Donde leo, meto la pata, comentaba de cuando en cuando. Fui testigo de las escenas más tragicómicas de mi vida, cuando en un pueblito del litoral le escuché a un compañero de trabajo, mientras temblaba la tierra, arrodillado sobre el suelo, gritar solemne hacia las nubes estáticas las frases de nuestro himno nacional Salve oh patria, mil veces oh patria. Y ocurrió el milagro: cesó el temblor a los pocos segundos, pero no la risa de los testigos. Yo poseo algunos poemas emblemáticos del Cholo Vallejo, que frecuentemente los leo para no olvidarme que el poeta padece mucho dolor, se impone a sí mismo un denodado sacrificio $y$, a la vez, desarrolla una enorme capacidad para asimilar la incomprensión, la indiferencia, la inopia y la sordera. Que al final, no obstante debatirse entre la elemental calidad de vida y las fuerzas oscuras o demasiado evidentes que tienden a sustraerle o a condicionar la luz interior, su práctica es infinitamente consoladora y custodia al poeta más que cualquier otra activi- 
dad o causa, aunque escribir sea un despilfarro de eternidades vitales y de energía, un hábito rutinario, casi costumbre, cuyos frutos maduran en el plazo remoto. La práctica de la escritura, es al final de todo, la única constancia de que el poeta hace mucho tiempo aceptó aquella pretensión y porfía de ir con la palabra más allá de la expresión y la comunicación del habla, e incluso del decir. En este sentido, la aseveración de Antonio Machado es pertinente: todo poeta debe crearse una metafísica que no necesita exponer, pero que ha de hallarse implícita en su obra. Adhiero a lo dicho por quien cree que al lector, al destinatario de la poesía, hay que inventarlo. Esto implica poseer o estar poseído por un convencimiento que mueva montañas o por una sagaz certidumbre en que, si logra un verso duende y burlón, ese verso llegará como un destello de espíritu y de carne a un alma despatarrada, proclive a la fascinación y al asombro. El lector, en algún recodo del azar espera ser inventado para convertirse él mismo en destino que inventa. Por ello el poeta al ser inventado por el destino, siempre ha escrito y escribirá para penetrar en su más íntimo interior y para escaparse y dejarse seducir por la vida y jugar con la muerte. Por apetitos místicos de trascendencia y dejarse alterar misteriosamente por la palabra para no morir como ilusión y reencarnarse como realidad en el corazón del mundo y cada vez reafirmar que nadie que no sea seducido por el verso seducirá a lo y los demás. Por nostalgia diabólica de perderse en las apariencias y por desahogarse sobre el único relieve de la anacronía. Contra la violencia de la disuasión, de lo neutro, del grado cero y a favor de algún sortilegio ante el cual las significaciones son vulnerables. Para detener el instante del juego total. En fin, para vivir la alteridad en la identidad y viceversa y para sobrevivirlas en el sentido de nido, vuelo, canto de hombre planetario como el poeta Carrera Andrade, por ejemplo, que pudo ofrecer una inagotable biografía para uso de los pájaros.

6.- Me alegra estar ajeno al orden del discurso. Me refiero a aquél de orden que se circunscribe en la definición de cuál es el gran canon poético, quiénes lo conforman y de qué manera su importancia coadyuva a apuntalar nombres con base en el afecto excluyente, el interés subjetivo, la arbitrariedad y el atolondrado desdén. Todo esto ocurre dentro de un ámbito de competencia obsesiva con la finalidad de ganar prestigio, vencer a ultranza las resistencias de la sensatez y la salud del lenguaje de los vivos. El lauro subliminal será el reconocimiento que otorga la cosa de la 
historia, la distancia entre significante y significado, el poder del cementerio, junto a los campeones ya muertos sobre el podio del canon. ¿Será que influyen socialmente estímulos nefastos como la elección del mejor ecuatoriano de todos los tiempos, ocurrida no hace mucho? Gran parte de los poemas canónicos, es obvio, se han descolorido, se han despoetizado, han devenido versos de museo, accesibles a todos y a nadie. Los poetas, a través de los ojos de los lectores, han agotado, poco a poco, las posibilidades rítmicas y nadie sabría hoy en día extraer de sus versos una respiración distinta, una mayor expansión de temas y contenidos, un contagio para el cambio de escritura o la huella de un pigmento personal. En su búsqueda, mientras vivían, pudieron hacer retroceder el límite de la expresión, mas no abolirlo. Emplearon las formas menos usadas e inventaron otras nuevas y asimismo combinaron, de una manera más o menos diestra, las ya conocidas. La mayor parte de esta poesía -me refiero a la de mi país de principios del siglo XX- salvo raras excepciones, es sublimemente mediocre y artificiosa e insufriblemente perfecta y ya empiezan a incomodar los síntomas de su parcial tumefacción. Aparte del plano meramente referencial, a mí me importa muy poco dicho canon, que como sabemos, con el paso del tiem- po se cuartea, tambalea, incesantemente, sufre un proceso de erosión y apolillamiento agresivo $\mathrm{y}$, al final las piedras se desmoronan y falsea el calicanto, porque como dice la misma canción no hay amor que dure mucho por más constante que sea. Me interesa muy particularmente lo entrañable de la poesía que cada poeta escribió, no sólo para mí sino para todos: a veces sólo un verso, una estrofa, en el mejor de los casos una unidad poemática completa. Es muy difícil que todo lo que ha escrito un poeta nos llegue con idéntica potencia, y dentro de su variedad, nos guste lo mismo que a los otros lectores. Considero que la calidad de los poemas, en última instancia, está condiciona$d a$ por el perfil del lector que es de algún modo el perfil semejante del poeta. El poeta a través de su poema busca un lector que se corresponda con su sensibilidad, sus valores vitales, su identidad asumida en el límite de la intuición creativa. De otro lado, el poeta, sobre todo es un lector. En este sentido, lo instintivo para él es leer antes que escribir. Por efecto de esta interacción no existen poemas malos o peores, ni buenos o excelentes, sino poemas oficiosos, versos eficaces que poseen una embriaguez inmanente, sea cual fuere la emoción que encubre o descubre al verdadero drama humano. Poesía al alcance de alguien, y en lo posible, de todos: esa 
es la oferta y, creo que en el fondo, esa es la demanda.

7.- Esto que acabo de señalar, por supuesto, no tiene relación con la discordia o afinidad seculares entre individuo y sociedad, entre poeta y desmadejado pensar de la época, entre prójimo y poder, entre persona y soportes de la civilización e, incluso, entre ciudadano y evanescencia del espacio público, cuyo discurso me interesa sobremanera para encontrar la exacta ubicación que me corresponde. Estoy en el lado de quienes piensan que en la actualidad hemos arribado a una situación patéticamente trágica, en la cual el poder que debía haber mimado y protegido al hombre lo ha humillado, lo ha mutilado, le ha separado el cuerpo del alma, lo ha desvalorizado, le ha mentido, lo ha condenado a la indefensión y le ha arriado su horizonte. El poeta, que es algo así como una trans-

Hay seres muy inteligentes que no saben pensar ni son poetas. versal condensación de lo humano, surge como una voz tenaz y discrepante del poder y de la sociedad. Cuando el poeta habla -o mejor, dice- no lo hace a la inconmensurable sociedad reunida en asamblea sino al hombre, de soledad a soledad, de silencio a silencio, de esencia de ser a esencia del ser. Paul Zumthor dice que el oyente escucha en el silencio de sí mismo esa voz que viene de otra parte; deja que resuene sus ondas, recoge sus modificaciones, con todo el razonamiento en suspenso. El poeta sólo reclama que el hombre se concentre en el para sí, en el sí mismo que es, que abandone las imposturas, los fraudes y las trampas que lo encandilan y lo entontecen: ideologías mesiánicas, moralismos de la enajenación, negocios de dictadura facilista o de democracia discutidora, tramoyas de prestigio y tentaciones oportunistas del más acá y del más allá. El poeta es un relegado de los esplendores del poder y un extrañado de lo decorativo y retórico: sólo desde esa condición le inquiere al hombre. El poeta no es catedrático de nada, no adoctrina en nada que sea principio o fin de nada, no evangeliza con ningún credo basado en la trascendencia utilitaria: sólo funda y coincide; crea, consolida y suscribe. La poesía es la respuesta a la agita- 
ción de una época donde cunde el síndrome entre los creadores que creen ser los últimos especimenes en este supuesto proceso irreversible de extinción de la poesía. Podrá no haber poetas, digo con el poeta Bécquer.-¿Podrá no haber poetas?-, digo yo, porque siempre habrá el tú de mí desde ti, tú de ti conmigo en único ambos. La poesía es para el poeta meollo del ser y permanente insinuación de su existencia, por eso es la legítima señal de salvación por vía de la reencarnación en el verso -si cabe el término-, ante un mundo que cíclicamente colapsa.

8. Acabo de emerger de una crisis valorativa, cuyo balance me ha inducido a creer que no debía apresurarme publicando lo escrito en todos estos años, hasta no haber estado seguro yo mismo de su calidad, autenticidad y vigencia. Este proceso me ha sido útil para afirmarme en el convencimiento de que para la poesía y la creación todo tamiz, alejamiento táctico y concentración son insuficientes. Parto del principio de que lo más difícil es asumir la sencillez y la modestia implícitas ante la complejidad y el misterio del lenguaje. Esta pretensión presupone una entrega a tiempo completo a la reflexión y a la creación, lo que no significa escribir prolíficamente. La poesía se hace sílaba tras sílaba, pero sílaba por sílaba no es poesía. Creo con Schiller que la creación no es realizada por el intelecto, sino por el juego del instinto, partiendo de la necesidad interior. Hay seres muy inteligentes que no saben pensar ni son poetas. Aunque sea la mente la que busca, con mucha frecuencia es la mano la que encuentra, dice un aforismo oriental. Debe ser por eso que a Baudelaire la inspiración le sorprendía escribiendo. Actualmente, los tópicos de mis libros son el amor, la ternura y las franjas intermedias del afecto. El parpadeo del desplazamiento del horizonte histórico y la contracción de la fábula posible. La fe coagulada que ha vuelto a licuarse para retornar de nuevo a las imágenes ávidas de mutación. La creencia, otra vez, en la unidad integral, en la estrella infusa en el charco, en la ola y en el cruce de nieblas. Lo fragmentario, el montaje unificador de la ciudad con lo discontinuo, lo abocetado, lo casi sucinto en las vidrieras y los espejos; los contrastes, más simultáneos que paralelos, del empezar siempre de nuevo, de la identidad y la otredad del ser, de la vulnerabilidad de la memoria y la cordura, de la caducidad del tiempo progresivo y del que se represa en la conciencia, de la nostalgia de un 
mundo más humano y, a la vez, la sensación de soledad y abandono. Considero que la poesía entraña la operación de autodefinirse, de especificarse $y$, en el fondo, esto es lo que encubren los claroscuros entre cada uno de mis versos. Al mismo tiempo he abandonado el fácil y el difícil moralismo, el paramento, la sensiblería, la solemnidad politiquera. Mi interés se orienta a adensar el sentido y darle profundidad al nivel donde se gesta la lucha por la actitud y la expresión, la sincronía y complemento de lo dicho y lo no dicho, de lo espontáneo y lo reflexivo, de la apoteosis y la caída, de lo posible y lo imposible. Es decir, la asunción de una permanente e incisiva auto exigencia. En este sentido, he ido comprendiendo que el problema a ser resuelto no es cómo ni dónde difundir mi obra, sino de credibilidad frente a mí mismo, aunque, claro está, a veces, ni siquiera esa credibilidad constituye garantía. ¿No será, detrás de todas las apariencias, este mí gran miedo? 